\title{
Article
}

\section{Comparative Analysis of Developed Rainfall Intensity-Duration-Frequency Curves for Erbil with Other Iraqi Urban Areas}

\author{
Dalshad Ahmed Kareem ${ }^{1}$, Aumed Rahman M Amen ${ }^{2}$, Andam Mustafa ${ }^{3, * \mathbb{D}}$, Mehmet Ishak Yüce ${ }^{4}$ \\ and Michał Szydłowski ${ }^{3}$ iD
}

1 Erbil Technology College, Erbil Polytechnic University, Erbil 44001, Iraq; dalshad.kareem@epu.edu.iq

2 Department of Civil Engineering, Faculty of Engineering, Soran University, Soran 44008, Iraq; aumedmamen@gmail.com

3 Faculty of Civil and Environmental Engineering, Gdansk University of Technology, Narutowicza 11/12, 80-233 Gdańsk, Poland; mszyd@pg.edu.pl

4 Department of Civil Engineering, Gaziantep University, Gaziantep 27310, Turkey; yuce@gantep.edu.tr

* Correspondence: andam.mustafa@pg.edu.pl; Tel.: +48-573-233-552

Citation: Kareem, D.A.; M Amen, A.R.; Mustafa, A.; Yüce, M.I.; Szydłowski, M. Comparative Analysis of Developed Rainfall Intensity-Duration-Frequency Curves for Erbil with Other Iraqi Urban Areas. Water 2022, 14, 419. https://doi.org/10.3390/w14030419 Academic Editor: Renato Morbidelli

Received: 22 December 2021

Accepted: 26 January 2022

Published: 29 January 2022

Publisher's Note: MDPI stays neutral with regard to jurisdictional claims in published maps and institutional affiliations.

Copyright: (C) 2022 by the authors. Licensee MDPI, Basel, Switzerland. This article is an open access article distributed under the terms and conditions of the Creative Commons Attribution (CC BY) license (https:// creativecommons.org/licenses/by/ $4.0 /)$.

\begin{abstract}
Rainfall Intensity-Duration-Frequency (IDF) relationships are widely used in water infrastructure design and construction. IDF curves represent the relationship between rainfall intensity, duration, and frequency, and are obtained by analyzing observed data. These relationships are critical for the safe design of flood protection structures, storm sewers, culverts, bridges, etc. In this study, the IDF curves and empirical IDF formulas for the city of Erbil were developed for the first time by employing the annual maximum rainfall data for a period of 39 years (1980-2018), which is the only available recorded data. Statistical techniques such as Gumbel and Log-Pearson Type III (LPT III) were utilized to determine the IDF curves and empirical equations from daily rainfall data for several standard durations and return periods. The correlation between the rainfall intensities obtained from IDF curves and the empirical formula presented a reliable match, with a coefficient of determination of $\left(R^{2}=1\right)$. The results were compared to previously developed IDF curves and empirical formulas in Iraqi cities to show their reliability. Moreover, the results can be an initial step for authorities to establish required guidelines in the studied area, and in the design process of the storm water infrastructure of urban basins in the future.
\end{abstract}

Keywords: extreme rainfall; rainfall intensity; IDF curves; Gumbel distribution; Log-Pearson Type III distribution; frequency analysis; return periods; Erbil; Iraq

\section{Introduction}

Rain is an important source of fresh water on Earth, provided by the long hydrological cycle; however, it can also be a source of natural disasters, such as urban flash floods. Al-Amri and Subyani [1] claimed that water project design is difficult in arid regions because rainfall is unpredictable and erratic in both time and space. This is also true for semi-arid regions. The precipitation varies significantly between the years, which makes it a challenge for water resources management [2]. Rainfall intensity-duration-frequency (IDF) relationships are graphical representations of the amount of water that falls within a given period of time in catchment areas [3]. Thus, they are critical for preventing flooding and, as a result, minimizing the loss of life, property, and the cost of water damage insurance and weather-related risk assessments. IDF curves have been estimated in developed countries since 1932, but they are still not available in many developing countries due to a lack of data. As Koutsoyiannis et al. [4] pointed out, the availability of accurate and long-term rainfall data in developed countries and the lack of such information in developing countries is the major factor in the construction of IDF curves. Many researchers in different parts 
of the world have developed IDF curves and empirical formulas [5-10]. Lima et al. [11] came up with a new way to figure out the parameters of a Generalized Extreme Value (GEV) distribution at the sub-daily level. They used the scaling-invariant property of rainfall duration versus intensity. When they looked at historical data, they found that the model was good at predicting IDF curves for both gauged and partially gauged sites. Global Satellite Mapping of Precipitation (GSMaP) and the Bartlett-Lewis rectangular pulses (BLRP) model, which were used by Sun et al. [12], disaggregate the daily in situ rainfall, which was then used to derive more accurate IDF curves. Kristvik et al. [13] used the concept of scale invariance to downscale the distribution of extreme precipitation from daily to sub-daily timescales in three Norwegian cities. From that, they derived the local-scale intensity-duration-frequency (IDF) curves for future precipitation. Some studies looked into how satellite-based precipitation could be used to make IDF curves [14,15]. Schardong et al. [16] conducted their research with the help of a web-based tool for the development of IDF curves under changing climate conditions at gauged and ungauged locations. Using the controlled random search method, Weinerowska-Bords [17] analyzed the practical issues associated with developing IDF curves and formulas (such as sample homogeneity and independence, and storm episode selection) for the development of the Gdańsk IDF-formula. Krvavica and Rubinić [18] investigated the effects of design storms and critical rainfall durations on flood prediction in partially urbanized catchments. In Saudi Arabia, which is considered an arid region, and the neighboring country of Iraq, in the southwest, researchers developed IDF relationships with different return periods in different parts of the country [1,19-22]. In Turkey, Deger and Yuce [23] analyzed the rainfall intensity-frequency of Gaziantep city, which is located in the northwest of the studied area. They expected their results to be useful for the local authorities. Şen [24] proposed a new method for constructing IDF curves based on the Annual Daily Maximum Rainfall (ADMR) data. The suggested methodology was applied to four ADMR records from meteorology stations in Turkey, in the Ceylanpinar region next to the Syrian border. In the west of the study area, using the Gumbel method, Hadadin [25] found a correlation between rainfall data and the intensity and duration of rain in the Mujib Basin in Jordan. In Iraq, starting from the north, Hamaamin [26] developed rainfall intensity-duration-frequency curves for Sulaymaniyah city, which is situated to the east of Erbil city. The study's findings revealed that the IDF curves computed with the coefficient of determination $\left(R^{2}=1\right)$ fit perfectly with the predicted values of rainfall intensities. Rainfall data for a number of stations in Northern Iraq was analyzed by Hasan and Saeed [27]. Mahdi and Mohamedmeki [28] found that the maximum rainfall intensity of $118.052 \mathrm{~mm} / \mathrm{hr}$ occurred at the duration of $0.25 \mathrm{~h}$ of the return period of 100 years when they analyzed IDF curves of the capital city Baghdad in the middle of Iraq. In the south of Iraq, IDF curves were estimated for the cities of Basrah, Najaf, and Nasiriyah by [29-31].

There have been more urban flash floods since 2010 in Erbil, and this has caused many sewer pipes to overflow, allowing sewage to escape and mix with storm water. As a result of the flooding, many small and local power generators lost their ability to generate electricity, resulting in more outages [32]. Mustafa et al. [33] presented extreme rainfall events as a cause of urban flash floods in Erbil. Moreover, according to Mustafa and Szydłowski [34,35], the city's urbanization is causing an increase in runoff peak and volume. As a result, the possibility of flash floods increases, posing a risk to life quality in the studied area, particularly in the city center. In fact, the hydrological monitoring system is important for the modeling of the flood risk in urban areas [36]. However, researchers have studied the effect of urbanization on floods not only in Erbil, but also in other cities of Iraq. Recently, Shareef and Abdulrazzaq [37] investigated a river flood to mitigate flood risk in the Fallujah district in Anbar Province, which is $69 \mathrm{~km}$ to the west of Baghdad, the capital city of Iraq. Some Iraqi cities have already developed their IDF curves and empirical formulas, but Erbil is the only one that has not yet done so.

The main objective of this study was to develop IDF curves for Erbil city center using daily rainfall depth measurement data from Erbil meteorological station. Additionally, 
empirical formulas were generated to estimate rainfall intensity for various return periods and rainfall durations. The obtained results were compared to previously developed IDF curves and empirical formulas in urban areas of Iraq, in order to show the reliance of the findings. While we recognize that the methods and equations used in this study are standard and have been used in other studies, the novelty of our work is that we developed IDF curves and formulas for a location where such work is not available. In particular, the findings of this study could help to improve water resource management in local urban areas, as well as the design and operation of storm water management systems. Moreover, the results of the study aim to assist authorities in Erbil municipality and the General Directorate of Water and Sewerage in implementing strategies and making good decisions.

\section{Materials and Methods}

\subsection{Study Area and Data Collection}

Erbil is the capital city of the Kurdistan Region of Iraq (KRI) and the second biggest city in the north of Iraq after Mosul. It lies approximately $350 \mathrm{~km}$ (220 miles) from Baghdad, the capital of Iraq. The total area of Erbil Province is $14,873.68 \mathrm{~km}^{2}$; however, the area considered as the studied area in this work is the center of the city (Figure 1). It lays on the coordinates: $36.11^{\prime} 28^{\prime \prime}$ latitude and $44.00^{\prime} 33^{\prime \prime}$ longitude, with an average elevation of $406 \mathrm{~m}$ above sea level [38]. There are long, hot summers and mild winters in Erbil, which has a Mediterranean climate. Aridity prevails during the summer months, with little to no precipitation between June and September. Wet and humid weather dominates the winter, with January being the wettest month of the year. The average annual temperature is around $21^{\circ} \mathrm{C}$, with temperatures ranging from 7 to $47^{\circ} \mathrm{C}$. Approximately $400 \mathrm{~mm}$ of rain falls on average each year, ranging from $200 \mathrm{~mm}$ in dry years to $650 \mathrm{~mm}$ in wet years, with the majority of the rainfall starting in October, increasing through December to January, and continuing until the end of May.

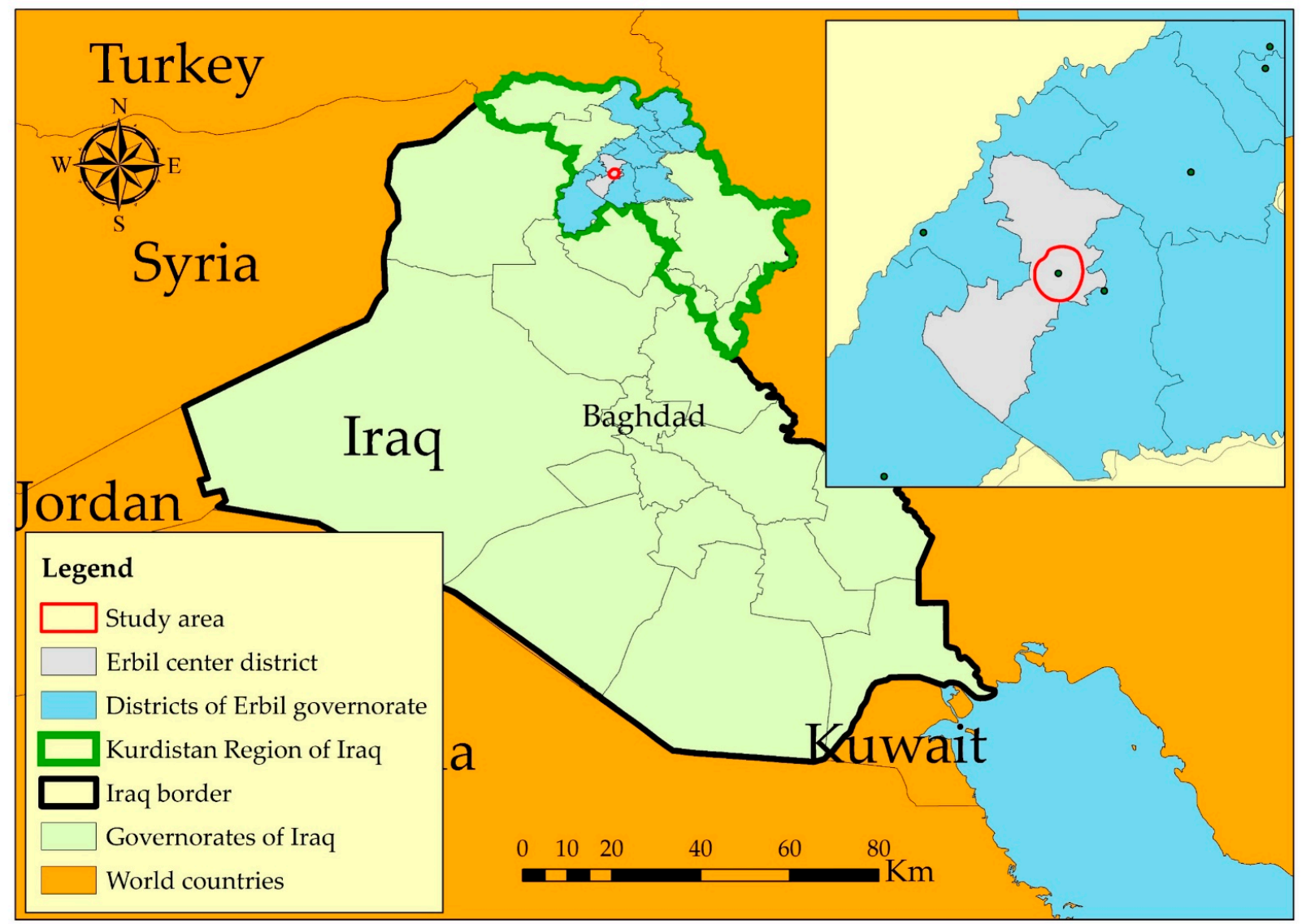

Figure 1. Study area. 
The meteorological dataset for this study has been obtained from the Climate Forecast System Reanalysis (CFSR) of the National Center for Environmental Prediction and General Directorate of Meteorology and Seismology in Kurdistan region/Iraq (GDMS). From 1980 to 1991, the dataset was obtained from the Climate Forecast System Reanalysis (CFSR) of the National Centre for Environmental Prediction. The General Directorate of Meteorology and Seismology in Kurdistan region/Iraq (GDMS) provided the dataset from 1992 to 2018. A classic rain gauge inside Erbil was used to record the rainfall data consistently and daily. The dataset consists of annual maximum daily $(24 \mathrm{~h})$ rainfall $(\mathrm{mm} / \mathrm{h})$; over 39 years from 1980 to 2018 were taken from [33] (see Table 1). The study area is big in size, a series of meteorological stations is required, but there is only one meteorological station available.

Table 1. Maximum daily rainfall for duration of 1980-2018.

\begin{tabular}{cccccc}
\hline No. & Year & 24 h Precipitation $(\mathbf{m m})$ & No. & Year & 24 h Precipitation $(\mathbf{m m})$ \\
\hline 1 & 1980 & 57.6 & 21 & 2000 & 46.4 \\
2 & 1981 & 40.9 & 22 & 2001 & 48.3 \\
3 & 1982 & 38.1 & 23 & 2002 & 59.2 \\
4 & 1983 & 32.9 & 24 & 2003 & 41.4 \\
5 & 1984 & 42.7 & 25 & 2004 & 40.6 \\
6 & 1985 & 72.7 & 26 & 2005 & 34 \\
7 & 1986 & 73.6 & 27 & 2006 & 103.9 \\
8 & 1987 & 31.8 & 28 & 2007 & 38 \\
9 & 1988 & 37.2 & 29 & 2008 & 41 \\
10 & 1989 & 48.4 & 30 & 2009 & 28.2 \\
11 & 1990 & 35.8 & 31 & 2010 & 33.8 \\
12 & 1991 & 62.4 & 32 & 2011 & 67 \\
13 & 1992 & 79 & 33 & 2012 & 71.8 \\
14 & 1993 & 57.9 & 34 & 2013 & 51 \\
15 & 1994 & 41.7 & 35 & 2014 & 55.8 \\
16 & 1995 & 75.7 & 36 & 2015 & 42.4 \\
17 & 1996 & 23.9 & 37 & 2016 & 31.4 \\
18 & 1997 & 35.8 & 38 & 2017 & 47.7 \\
19 & 1998 & 36.8 & 39 & 2018 & \\
20 & 1999 & 28.3 & & &
\end{tabular}

\subsection{Precipitation Duration Reduction Formula}

The only available rainfall data for Erbil city is the annual maximum $24 \mathrm{~h}$ measurements for a period of 39 years. Indeed, there are two ways to develop IDF curves for standard periods: either by obtaining detailed rainfall data from meteorological stations on short timescales (such kinds of data can be obtained only from automatic rain gauges) or by downscaling annual maximum rainfall from classic rain gauges to shorter durations. In order to obtain IDF curves for the study area, annual maximum rainfall data for standard periods of 10, 20, 30, 60, 120, 180,360, and $720 \mathrm{~min}$ is required. Due to the lack of these standard times, the Indian Meteorological Department (IMD) utilized Equation (1) to determine the rainfall data for periods shorter than $24 \mathrm{~h}$ [39]. The IMD method is simply the application of an empirical formula for downscaling the amount of precipitation falling on a daily or $24 \mathrm{~h}$ basis into shorter-duration precipitations. Rainfall analysis using the IMD method can be performed in stations where there are no automated rain gauges that can record both rainfall amount and duration data at the same time, but where there are rain gauges that can record data of cumulated $24 \mathrm{~h}$ rainfall amounts:

$$
P_{i}=P_{24}\left[\frac{t}{24}\right]^{\left(\frac{1}{3}\right)}
$$

where $P_{i}$ is the required precipitation depth for a duration less than $24 \mathrm{~h}$ in $\mathrm{mm}, P_{24}$ is the daily precipitation depth in $\mathrm{mm}$, and $t$ is the required duration time in hours. 


\subsection{Frequency Distribution and the Development of IDF Curves}

An analysis of the dataset for the past 39-year period has been conducted utilizing existing rainfall data and statistical tools to derive the intensity-duration-frequency relationships. Estimates of rainfall intensities over various timescales and recurrence intervals have been used to construct the IDF relationships. For example, the Generalized Extreme Value (GEV), normal, lognormal, Gumbel, and Log-Pearson Type III distributions are widely used in many parts of the world $[3,9,21,22,25,40-42]$. The relationship between rainfall intensity, storm duration, and return periods from rainfall data for the study area was developed using the following two common frequency analysis techniques.

\subsubsection{Gumbel Distribution}

The Gumbel method was established by the German mathematician Emil Gumbel, and has been widely used for modeling extreme events in hydrology and other fields [43,44]. Kotz and A Nadarajah [45] published a book that details this distribution and lists over 50 applications, ranging from accelerated life testing to earthquakes, floods, horse racing, rainfall, supermarket queues, sea currents, wind speeds, and track race records. This method was chosen to perform the flood probability analysis because it has become the most widely used distribution for IDF [46-49]. As Elsebaie [22] pointed out, the Gumbel method is a simple and straightforward approach that can be applied in extreme events (maximum value or peak rainfalls). The frequency of precipitation $P_{T}$ (in $\mathrm{mm}$ ) for each duration with a specified return period $T$ (in years) is given by the following equation:

$$
P_{T}=P_{\text {ave }}+K \times S
$$

$K$ is the Gumbel frequency factor, which can be found by:

$$
K=-\frac{\sqrt{6}}{\pi}\left[0.577+\ln \left[\ln \left[\frac{T}{T-1}\right]\right]\right]
$$

where $P_{\text {ave }}$ is the average of the maximum precipitation corresponding to a specific duration.

The arithmetic average in Equation (1) is used when using the Gumbel distribution.

$$
P_{\text {ave }}=\frac{1}{n} \sum_{i=n}^{n} P_{i}
$$

The individual extreme value of rainfall is $P_{i}$, and the number of events or years of record is $n$. The following equation is used to calculate the standard deviation:

$$
S=\left[\frac{1}{n-1} \sum_{i=1}^{n}\left(P_{i}-P_{\text {ave }}\right)^{2}\right]^{1 / 2}
$$

where $S$ is the standard deviation of $P_{T}$ data. The frequency factor $(K)$, which is a function of the return period and sample size, when multiplied by the standard deviation gives the departure from the average rainfall of a desired return period. The rainfall intensity $I_{T}(\mathrm{~mm} / \mathrm{h})$ for the return period $T_{d}$ is then calculated as follows:

$$
I_{T}=\frac{P_{T}}{T_{d}}
$$

where $T_{d}$ is the duration in hours.

\subsubsection{Log-Pearson Type III}

As previously stated in this section, there are several methods for determining the intensity-duration relationship, with Log-Pearson Type III (LPT III) being one of them. LPT III contains a logarithm of the measured values. The mean and the standard deviation are 
determined using the logarithmically transformed data. The precipitation frequency is calculated using the LPT III method in the same way as the Gumbel method. The following is a simplified expression for the latter distribution:

$$
\begin{gathered}
P^{*}=\log \left(P_{i}\right) \\
P_{T}^{*}=P_{\text {ave }}^{*}+K_{T} S^{*} \\
P_{\text {ave }}^{*}=\frac{1}{n} \sum_{i=n}^{n} P^{*} \\
S^{*}=\left[\frac{1}{n-1} \sum_{i=1}^{n}\left(P^{*}-P_{\text {ave }}^{*}\right)^{2}\right]^{1 / 2}
\end{gathered}
$$

$P_{T}^{*}, P_{\text {ave }}^{*}$, and $S^{*}$ are the same as before, but based on logarithmically transformed $P_{i}$ values; i.e., $P^{*}$ of Equation (7). The Pearson frequency factor $K_{T}$ is determined by the return period $(T)$ and the skewness coefficient $\left(C_{S}\right)$.

The frequency factor for this distribution must be computed using the skewness coefficient $C_{s}$. Equation (11) calculates the skewness coefficient:

$$
C_{s}=\frac{n \sum_{i}^{n i}\left(P^{*}-P_{\text {ave }}^{*}\right)^{3}}{(n-1)(n-2)\left(S^{*}\right)^{3}}
$$

$K_{T}$ values can be obtained from tables in many sources of hydrologic data; such as [50]. By knowing the skewness coefficient and the recurrence interval, the frequency factor $K_{T}$ for the LPT III distribution can be extracted. The antilog of the solution in Equation (8) represents the estimated extreme value for the given return period.

\subsection{Derivation of IDF Empirical Formula}

The relationship between the rainfall intensity $(I)$, rainfall duration $(t)$, and return period $(T)$ is described by the IDF empirical formula. Both the Gumbel distribution method and the Log-Pearson Type III method can use the formula. To derive an equation for calculating the rainfall intensity $(I)$ for the study area, there are several steps that must be completed in order to establish an equation that is suitable for the calculation of rainfall intensity for a specific recurrence interval and specific rainfall period, which is dependent primarily on the results obtained from the IDF curves. The steps below are used to derive the equation:

$$
I=\frac{C T^{m}}{t^{a}}
$$

where $I$ is the intensity of rainfall $(\mathrm{mm} / \mathrm{h}), t$ is the duration of rainfall (minutes), $T$ is the return period (years), and the constants $(C, m$, and $a)$ are empirical parameters that are dependent on precipitation data, and the shape, size, and location of the study area, and can be obtained by using the logarithmic transformation of Equation (12). After performing a logarithmic transformation on Equation (12), we can obtain Equation (13):

$$
\log I=\log \left(C T^{m}\right)-a \log t
$$

Assuming $\left(C T^{m}=K\right)$, Equation (13) can be rewritten as in Equation (14):

$$
\log I=\log (K)-a \log t
$$

Plotting the logarithm of precipitation intensity $(\log I)$ value against the logarithm of time $(\log t)$ value will present a linear relationship. To find the linear relationship's slope (the average value of constant $a$ for all return periods), solve Equation (13), where represents the constant $a$, and $\log (K)$ in Equation (14) represents the intercept from each return period's plot. The linear relationship's slope will be displayed. 
Finding $C$ and $m$ is as simple as plotting the logarithmic intercept $\left(\log C T^{m}\right)$ against the logarithmic return period $(\log T)$ in a new graph in Equation (16).

Assuming that:

$$
K=C T^{m}
$$

taking the $\log$ of both sides of Equation (15) will result in the following Equation (16):

$$
\log K=\log C-m \log T
$$

Plotting $\log K$ and $\log T$ in Equation (16), a linear equation of the plot can be obtained, then the $m$ value can be found, which represents the slope of the linear relationship. The value of the anti-log of the intercept from the plotted curve represents the $C$ coefficient for Equation (12).

\subsection{Goodness of Fit}

With this test, we can determine how well the observed frequency of occurrence in a sample corresponds to the expected frequencies obtained from the hypothesized distributions in a sample. It is possible to perform a goodness-of-fit test between observed and expected frequencies using the chi-square quantity, which is expressed as:

$$
\chi^{2}=\sum_{i=1}^{k}\left(O_{i}-E_{i}\right)^{2} / E_{i}
$$

where $\chi^{2}$ is a random variable with a chi-square sampling distribution. The observed and expected frequencies of class intervals are shown in the histogram by $O_{i}$ and $E_{i}$. The number of class intervals is $k$. The $\chi^{2}$ value is small if the observed frequencies match the expected frequencies; otherwise, it is large. A good fit accepts the null hypothesis, while a bad fit reject it. The critical region will thus be in the chi-square distribution's right tail. The critical value is found using readily available chi-square tables, and the critical region is $\chi^{2}>[20,22,41]$.

\section{Results and Discussion}

The IDF curves were developed using 39 years of rainfall intensity records for the city center of Erbil in the KRI. The IDF curves are utilized to assist in the design of drainage structures for any type of engineering project. The curves enable the engineers from local authorities to design flood control measures that are both safe and economical. The two techniques (Gumbel and LPT III) were used to estimate rainfall in $\mathrm{mm}$ and their intensities in millimeters per hour $(\mathrm{mm} / \mathrm{h})$ for a variety of return periods and different durations. The results of the Gumbel method are listed in Table 2. It has been demonstrated in all of them that the rainfall intensity decreased with an increase in the rainfall duration at the same return period, and that the rainfall intensity increased with an increase in the return period. Figures 2 and 3 show the IDF curves using the Gumbel method on an ordinary scale and on the log-log scale (for $T=2,5,10,25,50,100$ years). The results of this study are compared to the findings of previous work. The results revealed that the intensity of rainfall determined using the Gumbel method for different return periods in Erbil is lower than that determined in Sulaymaniyah and higher than that calculated in Baghdad and Basrah $[26,29,30]$. As an example, for a two-year return period and a duration of $60 \mathrm{~min}$, the rainfall intensity in Erbil was $15.583 \mathrm{~mm} / \mathrm{h}$, while in Sulaymaniyah, which is located in the east of the study area and higher in elevation, the rainfall intensity was $20.21 \mathrm{~mm} / \mathrm{h}$, but in Baghdad, in the middle of Iraq, the amount decreased to about $11 \mathrm{~mm} / \mathrm{h}$ and in Basrah decreased even further. 
Table 2. Rainfall intensities calculated using the Gumbel method for various standard time scales and return periods.

\begin{tabular}{|c|c|c|c|c|c|c|c|c|c|}
\hline \multirow[b]{3}{*}{$\operatorname{Tr}$ (years) } & \multicolumn{3}{|c|}{$10 \mathrm{~min}$} & \multicolumn{3}{|c|}{$20 \mathrm{~min}$} & \multicolumn{3}{|c|}{$30 \mathrm{~min}$} \\
\hline & \multicolumn{2}{|c|}{$P_{a v e}=9.121$} & \multirow{2}{*}{$\begin{array}{c}S=3.326 \\
I_{T}\end{array}$} & \multicolumn{2}{|c|}{$\boldsymbol{P}_{\text {ave }}=11.492$} & \multirow{2}{*}{$\begin{array}{c}S=4.190 \\
I_{T}\end{array}$} & \multicolumn{2}{|c|}{$P_{a v e}=13.155$} & \multirow{2}{*}{$\begin{array}{c}S=4.796 \\
\boldsymbol{I}_{T}\end{array}$} \\
\hline & K & $\boldsymbol{P}_{T}$ & & K & $P_{T}$ & & K & $P_{T}$ & \\
\hline 2 & -0.164 & 8.576 & 51.454 & -0.164 & 10.805 & 32.414 & -0.164 & 12.368 & 24.736 \\
\hline 5 & 0.719 & 11.513 & 69.080 & 0.719 & 14.506 & 43.518 & 0.719 & 16.605 & 33.210 \\
\hline 10 & 1.305 & 13.459 & 80.757 & 1.305 & 16.958 & 50.874 & 1.305 & 19.412 & 38.824 \\
\hline 25 & 2.044 & 15.918 & 95.506 & 2.044 & 20.055 & 60.165 & 2.044 & 22.957 & 45.915 \\
\hline 50 & 2.592 & 17.742 & 106.451 & 2.592 & 22.353 & 67.060 & 2.592 & 25.588 & 51.176 \\
\hline \multirow[t]{4}{*}{100} & 3.137 & 19.552 & 117.313 & 3.137 & 24.634 & 73.903 & 3.137 & 28.199 & 56.398 \\
\hline & \multicolumn{3}{|c|}{$60 \mathrm{~min}$} & \multicolumn{3}{|c|}{$120 \mathrm{~min}$} & \multicolumn{3}{|c|}{$180 \mathrm{~min}$} \\
\hline & \multicolumn{2}{|c|}{$\boldsymbol{P}_{\text {ave }}=16.574$} & $S=6.043$ & \multicolumn{2}{|c|}{$P_{\text {ave }}=20.882$} & $S=7.614$ & \multicolumn{2}{|c|}{$\boldsymbol{P}_{\text {ave }}=23.904$} & $S=8.715$ \\
\hline & K & $P_{T}$ & $I_{T}$ & K & $P_{T}$ & $I_{T}$ & K & $P_{T}$ & $I_{T}$ \\
\hline 2 & -0.164 & 15.583 & 15.583 & -0.164 & 19.633 & 9.817 & -0.164 & 22.475 & 7.492 \\
\hline 5 & 0.719 & 20.921 & 20.921 & 0.719 & 26.359 & 13.180 & 0.719 & 30.174 & 10.058 \\
\hline 10 & 1.305 & 24.458 & 24.458 & 1.305 & 30.815 & 15.407 & 1.305 & 35.274 & 11.758 \\
\hline 25 & 2.044 & 28.924 & 28.924 & 2.044 & 36.442 & 18.221 & 2.044 & 41.716 & 13.905 \\
\hline 50 & 2.592 & 32.239 & 32.239 & 2.592 & 40.619 & 20.309 & 2.592 & 46.497 & 15.499 \\
\hline \multirow[t]{4}{*}{100} & 3.137 & 35.529 & 35.529 & 3.137 & 44.763 & 22.382 & 3.137 & 51.241 & 17.080 \\
\hline & \multicolumn{3}{|c|}{$360 \mathrm{~min}$} & \multicolumn{3}{|c|}{$720 \mathrm{~min}$} & \multicolumn{3}{|c|}{$1440 \mathrm{~min}$} \\
\hline & \multicolumn{2}{|c|}{$P_{\text {ave }}=30.117$} & $S=10.981$ & \multicolumn{2}{|c|}{$P_{\text {ave }}=37.945$} & $S=13.835$ & \multicolumn{2}{|c|}{$\boldsymbol{P}_{\text {ave }}=42.638$} & $S=16.877$ \\
\hline & $\mathrm{K}$ & $P_{T}$ & $I_{T}$ & K & $P_{T}$ & $I_{T}$ & $\mathrm{~K}$ & $P_{T}$ & $I_{T}$ \\
\hline 2 & -0.164 & 28.316 & 4.719 & -0.164 & 35.676 & 2.973 & -0.164 & 39.870 & 1.661 \\
\hline 5 & 0.719 & 38.016 & 6.336 & 0.719 & 47.898 & 3.991 & 0.719 & 54.779 & 2.282 \\
\hline 10 & 1.305 & 44.442 & 7.407 & 1.305 & 55.994 & 4.666 & 1.305 & 64.655 & 2.694 \\
\hline 25 & 2.044 & 52.559 & 8.760 & 2.044 & 66.220 & 5.518 & 2.044 & 77.131 & 3.214 \\
\hline 50 & 2.592 & 58.582 & 9.764 & 2.592 & 73.809 & 6.151 & 2.592 & 86.388 & 3.599 \\
\hline 100 & 3.137 & 64.560 & 10.760 & 3.137 & 81.340 & 6.778 & 3.137 & 95.576 & 3.982 \\
\hline
\end{tabular}

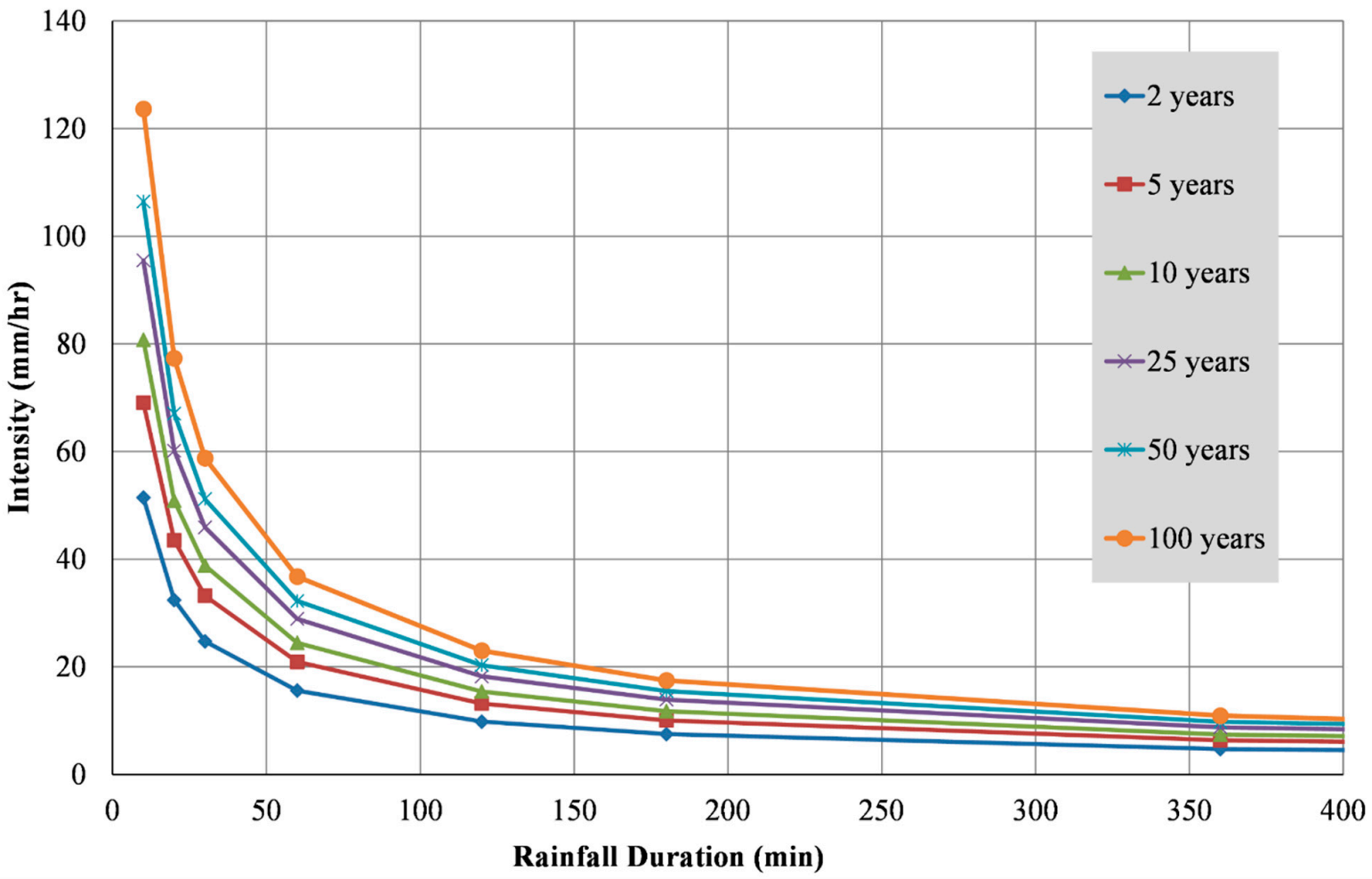

Figure 2. IDF curves generated using the Gumbel method on an ordinary scale. 


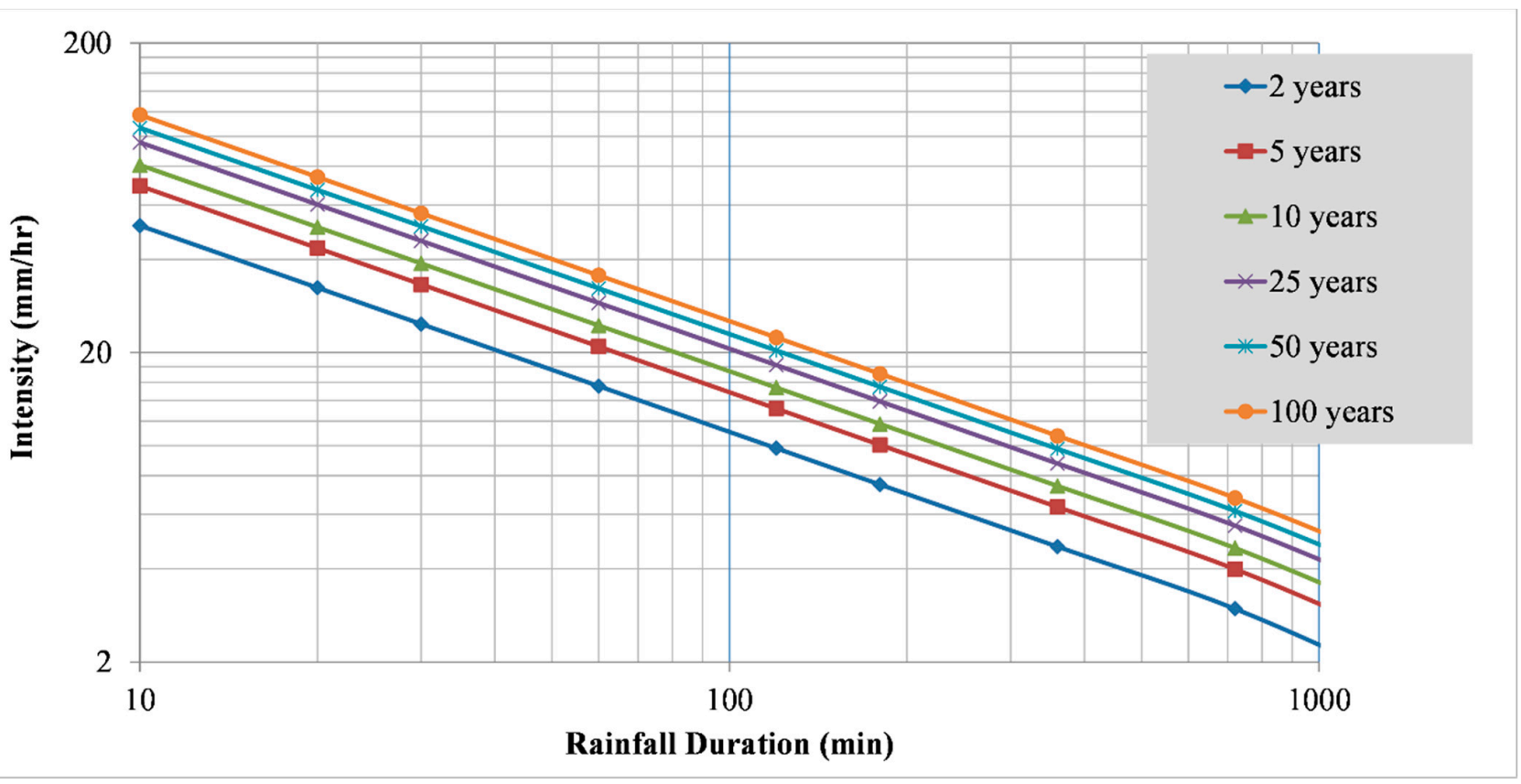

Figure 3. IDF curves generated using the Gumbel method on log-log scale.

A possible explanation for these results is because of the different climates of the mentioned locations, and their elevation above sea level. In fact, the average annual rainfall in Iraq is $154 \mathrm{~mm}$, but it varies widely across the country, from less than $100 \mathrm{~mm}$ in the south to more than $1200 \mathrm{~mm}$ in the northeast. The rainy season is limited to the months of October to April. Salman et al. [51] divide Iraq into four zones based on topography and climate (Figure 4): (1) Zone-I encompasses the mountainous region in the north and northeast ( $21 \%$ of the country) with a Mediterranean climate; (2) Zone-II encompasses the undulating land in the south and west $(9.6 \%)$ with a steppe climate; (3) Zone-III encompasses the western Plateau in the west, which is an extension of the Syrian and Arabian deserts (39.2\%) having a continental desert climate; and (4) Zone-IV covers the great Mesopotamian plain in the center and the south (30.2\%) having a subtropical semi-arid climate. Moreover, $\mathrm{Al}-$ Ansari [52] indicated that Iraq is shaped like a basin on the topographic map, containing the great Mesopotamian plains of the Tigris and Euphrates rivers. The climate is predominantly continental, subtropical, and semi-arid, with a Mediterranean climate in the north and northeastern mountainous regions. As is obvious, Iraq's climate divisions have an effect on the annual rainfall in each province. For example, the annual rainfall in Erbil, the study area is approximately $419.2 \mathrm{~mm}$, while in Sulaymaniyah, the average annual precipitation varies between $328 \mathrm{~mm}$ in dry years and $848 \mathrm{~mm}$ in wet years [26]; both provinces are located in Zone I, which is considered to have a Mediterranean climate. Baghdad, in the middle of Iraq, gains an annual rainfall depth of around $280 \mathrm{~mm}$ [28]. The average annual precipitation in Nasiriyah Province's central district from 1965 to 2015 was 117.64 [51]. The mean annual precipitation in the central district of Basrah Province from 1965 to 2015 was $131.65 \mathrm{~mm}$. Those respectively mentioned provinces are located in Zone IV, which is considered to have a subtropical, semi-arid climate [51]. Al-Ansari [53] classified Iraq into four regions based on the land's topography (Mountain Region, Plateau and Hills Regions, the Mesopotamian plain, and Jazera and Western Plateau). Erbil city center could be defined as being in the Plateau and Hills Regions; however, the northern and north eastern parts of Erbil Province are considered as the Mountain Region according to the Al-Ansari [53] classification. Figure 5 shows the elevation above sea level (ASL) and the administrative boundaries of the Iraqi Provinces.

The results of the LPT III method are listed in Table 3. Additionally, the results of this method, which were similar to those obtained from the Gumbel method, revealed that 
the rainfall intensity decreased with an increase in the rainfall duration in the same return period, and that the rainfall intensity increased with an increase in the return period. It was demonstrated that there were minor discrepancies in the results obtained using the two methods. The Gumbel method produces slightly higher results than LPT III for short return periods such as two, five, and ten years. While the situation becomes contradictory when the return period is increased to 25,50 , or 100 years, as the LPT III method produces slightly higher results than the Gumbel method. However, the LPT III method is believed to be more accurate because it takes into account the skewness of the data distribution.

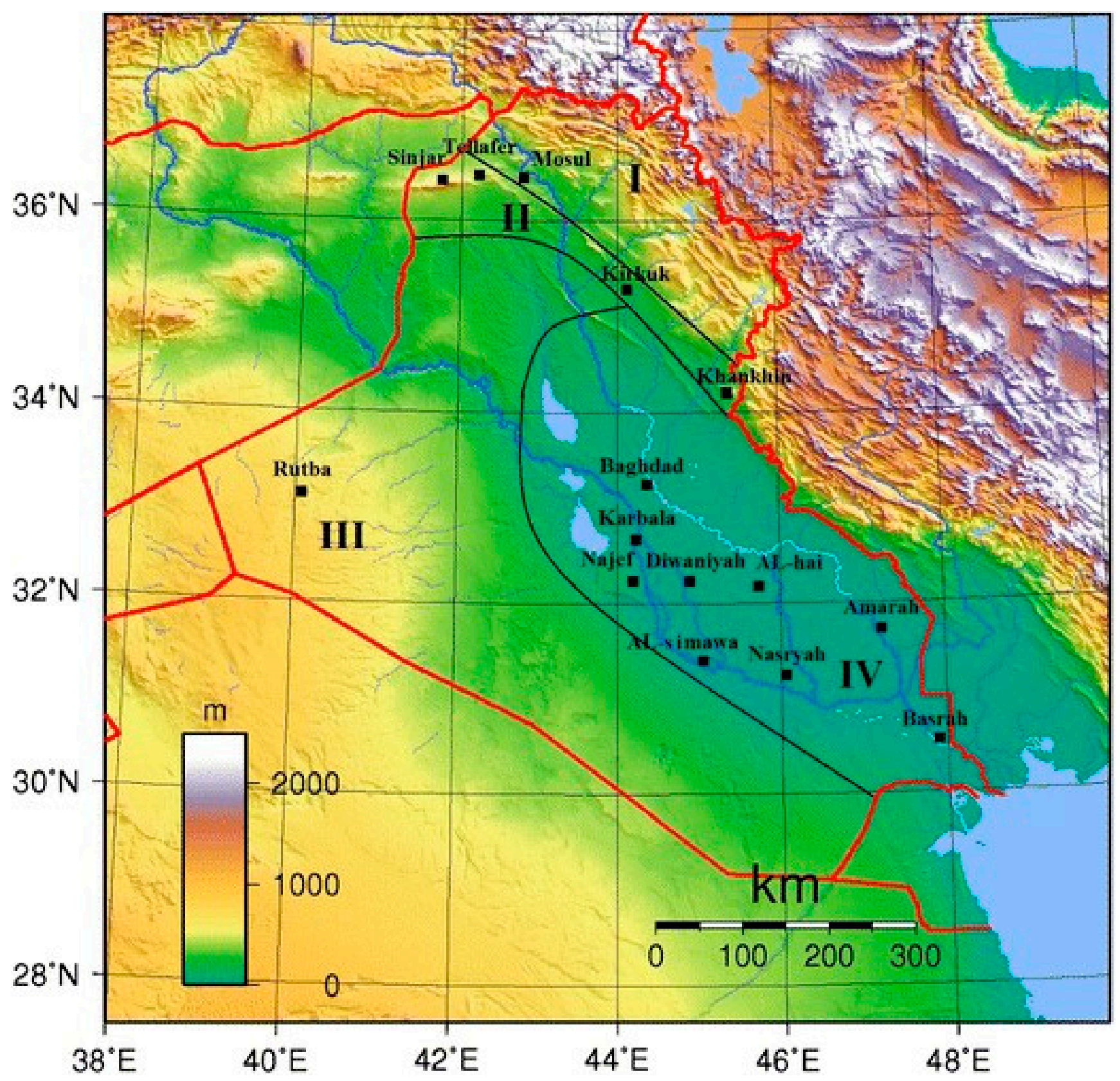

Figure 4. Climate zones in Iraq [52]. 


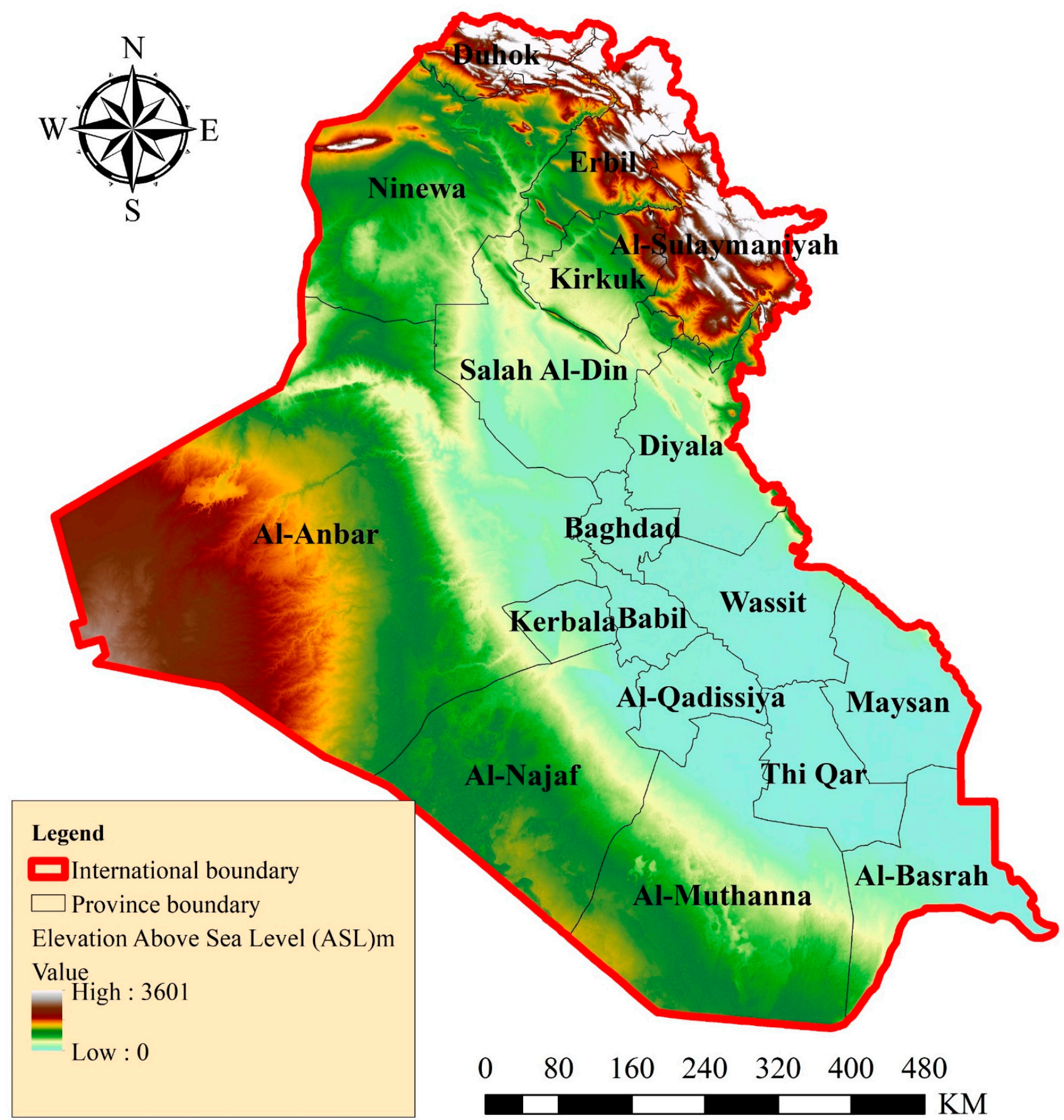

Figure 5. Topography and administrative boundaries of the Iraqi Provinces.

Al Hassoun [21] recommended that when accuracy is required in storm design studies, the results of the LPT III method be used. Figures 6 and 7 show the intensity-durationfrequency (IDF) curves using the Gumbel method on an ordinary scale and on the log-log scale (for $T=2,5,10,25,50,100$ years). The findings of that study are consistent with the findings of previous studies conducted in some parts of the study area and neighboring countries, according to the researchers. 
Table 3. Rainfall intensities calculated using the LPT III method for various standard time scales and return periods.

\begin{tabular}{|c|c|c|c|c|c|c|c|c|c|c|}
\hline \multirow[b]{3}{*}{$\operatorname{Tr}$ (years) } & \multirow[b]{3}{*}{ K } & \multicolumn{3}{|c|}{$10 \mathrm{~min}$} & \multicolumn{3}{|c|}{$20 \mathrm{~min}$} & \multicolumn{3}{|c|}{$30 \mathrm{~min}$} \\
\hline & & \multicolumn{2}{|c|}{$P_{a v e}=9.121$} & \multirow{2}{*}{$\begin{array}{c}S=3.326 \\
I_{T}\end{array}$} & \multicolumn{2}{|c|}{$\boldsymbol{P}_{\text {ave }}=11.492$} & \multirow{2}{*}{$\begin{array}{c}S=4.190 \\
I_{T}\end{array}$} & \multicolumn{2}{|c|}{$P_{\text {ave }}=13.155$} & \multirow{2}{*}{$\begin{array}{c}S=4.796 \\
I_{T}\end{array}$} \\
\hline & & $P_{T}^{*}$ & $P_{T}$ & & $P_{T}^{*}$ & $P_{T}$ & & $P_{T}^{*}$ & $P_{T}$ & \\
\hline 2 & -0.073 & 0.924 & 8.399 & 50.393 & 1.025 & 10.582 & 31.745 & 1.083 & 12.113 & 24.226 \\
\hline 5 & 0.852 & 1.060 & 11.477 & 68.861 & 1.160 & 14.460 & 43.380 & 1.219 & 16.552 & 33.105 \\
\hline 10 & 1.319 & 1.128 & 13.436 & 80.613 & 1.229 & 16.928 & 50.783 & 1.287 & 19.377 & 38.755 \\
\hline 25 & 1.890 & 1.212 & 16.291 & 97.745 & 1.312 & 20.525 & 61.575 & 1.371 & 23.495 & 46.991 \\
\hline 50 & 2.280 & 1.269 & 18.582 & 111.495 & 1.369 & 23.412 & 70.237 & 1.428 & 26.801 & 53.601 \\
\hline \multirow[t]{4}{*}{100} & 2.640 & 1.322 & 20.983 & 125.898 & 1.422 & 26.437 & 79.311 & 1.481 & 30.263 & 60.525 \\
\hline & & \multicolumn{3}{|c|}{$60 \mathrm{~min}$} & \multicolumn{3}{|c|}{$120 \mathrm{~min}$} & \multicolumn{3}{|c|}{$180 \mathrm{~min}$} \\
\hline & & \multicolumn{2}{|c|}{$P_{a v e}=16.574$} & $S=6.043$ & \multicolumn{2}{|c|}{$P_{\text {ave }}=20.882$} & $S=7.614$ & \multicolumn{2}{|c|}{$P_{\text {ave }}=23.904$} & $S=8.715$ \\
\hline & $\mathrm{K}$ & $P_{T}^{*}$ & $P_{T}$ & $I_{T}$ & $P_{T}^{*}$ & $P_{T}$ & $I_{T}$ & $P_{T}^{*}$ & $P_{T}$ & $I_{T}$ \\
\hline 2 & -0.073 & 1.184 & 15.262 & 15.262 & 1.284 & 19.228 & 9.614 & 1.343 & 22.011 & 7.337 \\
\hline 5 & 0.852 & 1.319 & 20.855 & 20.855 & 1.420 & 26.275 & 13.138 & 1.478 & 30.078 & 10.026 \\
\hline 10 & 1.319 & 1.388 & 24.414 & 24.414 & 1.488 & 30.760 & 15.380 & 1.547 & 35.211 & 11.737 \\
\hline 25 & 1.890 & 1.471 & 29.602 & 29.602 & 1.572 & 37.297 & 18.648 & 1.630 & 42.694 & 14.231 \\
\hline 50 & 2.280 & 1.528 & 33.767 & 33.767 & 1.629 & 42.543 & 21.272 & 1.688 & 48.700 & 16.233 \\
\hline \multirow[t]{3}{*}{100} & 2.640 & 1.581 & 38.129 & 38.129 & 1.682 & 48.039 & 24.020 & 1.740 & 54.991 & 18.330 \\
\hline & & \multicolumn{3}{|c|}{$360 \mathrm{~min}$} & \multicolumn{3}{|c|}{$720 \mathrm{~min}$} & \multicolumn{3}{|c|}{$1440 \mathrm{~min}$} \\
\hline & & \multicolumn{2}{|c|}{$P_{a v e}=30.117$} & $S=10.981$ & \multicolumn{2}{|c|}{$\boldsymbol{P}_{\text {ave }}=37.945$} & $S=13.835$ & \multicolumn{2}{|c|}{$P_{\text {ave }}=42.638$} & $S=16.877$ \\
\hline 2 & -0.073 & 1.443 & 27.732 & 4.622 & 1.543 & 34.940 & 2.912 & 1.644 & 44.022 & 1.834 \\
\hline 5 & 0.852 & 1.579 & 37.896 & 6.316 & 1.679 & 47.746 & 3.979 & 1.779 & 60.156 & 2.506 \\
\hline 10 & 1.319 & 1.647 & 44.363 & 7.394 & 1.747 & 55.894 & 4.658 & 1.848 & 70.422 & 2.934 \\
\hline 25 & 1.890 & 1.731 & 53.791 & 8.965 & 1.831 & 67.773 & 5.648 & 1.931 & 85.388 & 3.558 \\
\hline 50 & 2.280 & 1.788 & 61.358 & 10.226 & 1.888 & 77.306 & 6.442 & 1.989 & 97.400 & 4.058 \\
\hline 100 & 2.640 & 1.841 & 69.284 & 11.547 & 1.941 & 87.293 & 7.274 & 2.041 & 109.982 & 4.583 \\
\hline
\end{tabular}

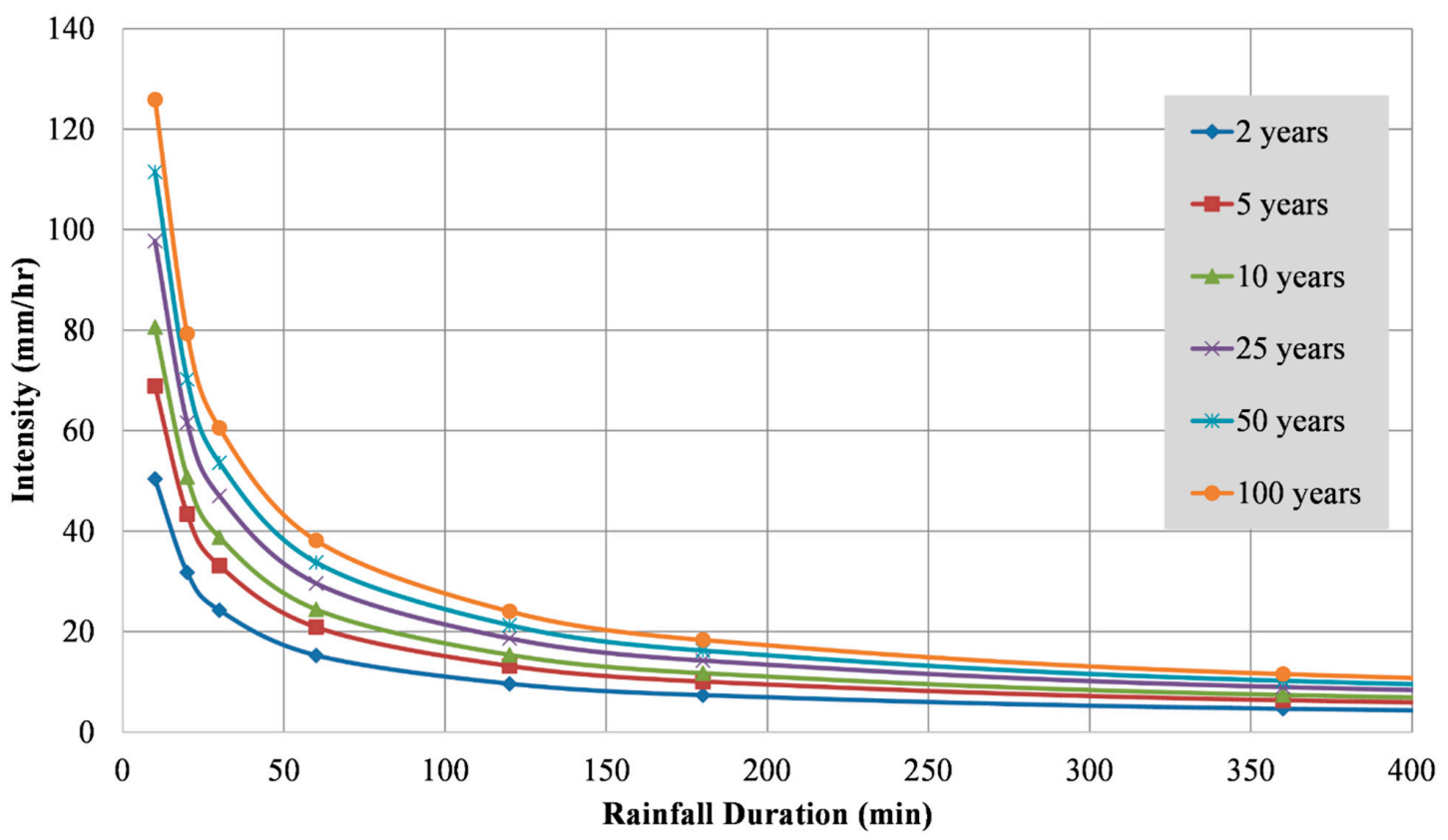

Figure 6. IDF curves generated using the LPT III method on an ordinary scale. 


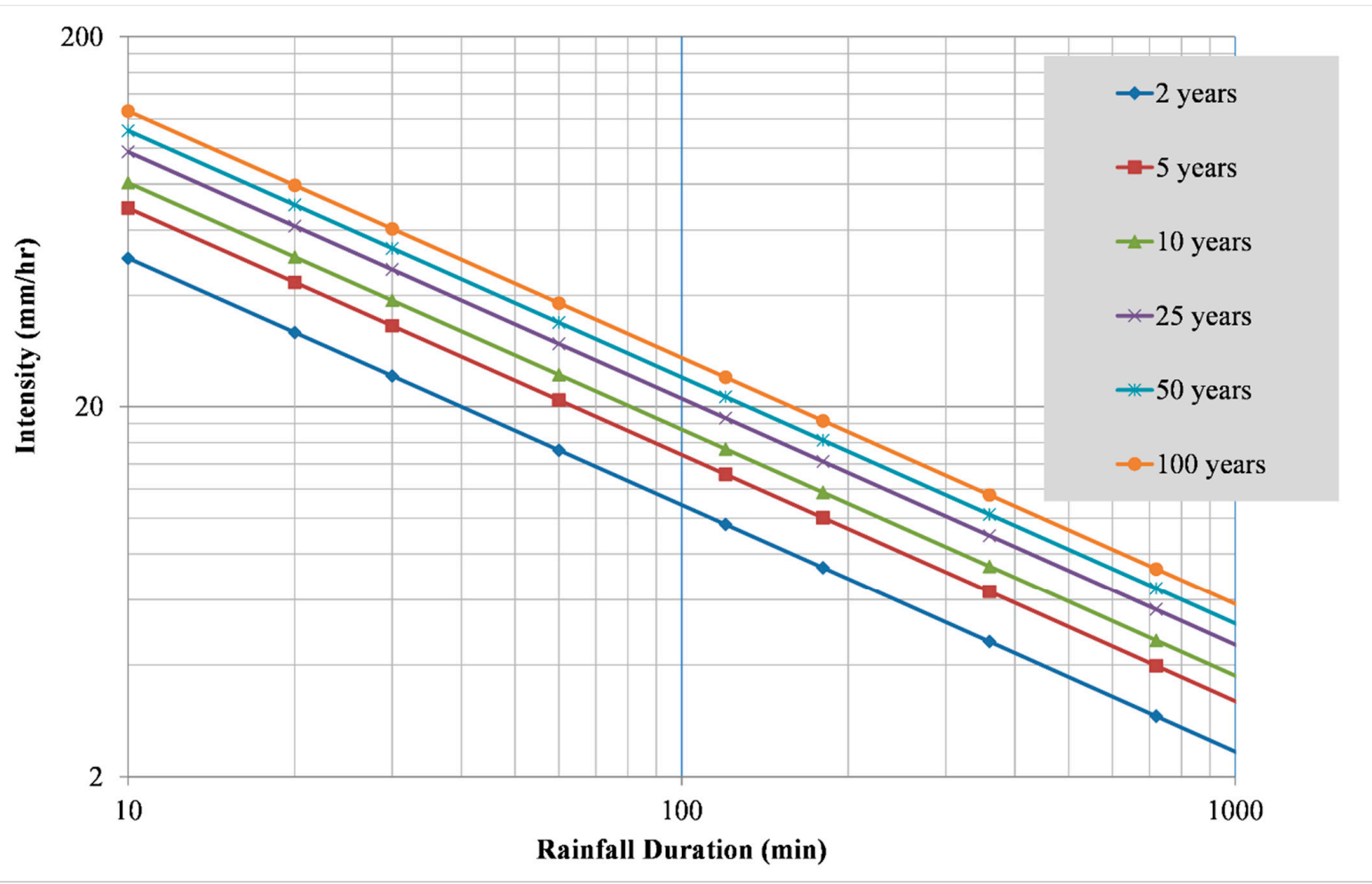

Figure 7. IDF curves generated using the LPT III method on a log-log scale.

The parameter values obtained from analyzing the IDF data using the two methods are shown in Table 4, and these values are used to derive formulas for the study area. In addition, the IDF equation parameters $(C, m$ and $a)$ obtained from the two distributions can be considered to be relatively close, with the exception of parameter $C$ from the Gumbel Theory distribution, which was slightly higher than in the other distribution (see Table 4). Moreover, the IDF equation parameters $(C, m$ and $a)$ of other Iraqi Provinces have been shown, revealing that the ( $m$ and $a$ ) parameters are slightly different between the developed IDF equations of all the mentioned governorates, while the parameter $(C)$ totally varies. Sulaymaniyah and Erbil have the highest (C) values of 288.4 and 234.020, respectively, using the Gumbel method. While in Baghdad, Nasiriyah, and Basrah, the value of the $(C)$ parameter decreased to $9.074,8.283$, and 7.95, respectively. This variation in parameter values in different Iraqi cities is evidence of the different climate conditions in each city, as explained earlier in this section.

Table 4. The values of the parameters that are used in the development of formulas in different cities of Iraq [26,28,29,31].

\begin{tabular}{cccc}
\hline Region & Parameter & Gumbel Method & LPT III Method \\
\hline \multirow{2}{*}{ Erbil } & $C$ & 234.020 & 212.790 \\
& $m$ & 0.200 & 0.228 \\
& $a$ & 0.681 & 0.667 \\
\hline \multirow{2}{*}{ Sulaymaniyah } & $C$ & 288.4 & \\
& $m$ & 0.191 & 7.044 \\
Baghdad & $a$ & 0.666 & 0.422 \\
& $C$ & 9.074 & 0.667 \\
\hline \multirow{2}{*}{ Nasiriyah } & $m$ & 0.318 & 7.565 \\
& $a$ & 0.667 & 0.350 \\
\hline \multirow{2}{*}{ Basrah } & $C$ & 8.283 & 0.674 \\
\hline
\end{tabular}


During the development of the IDF empirical formulas, a logarithmic conversion was applied to the precipitation parameters for both methods, which allowed the relationship to be converted into a linear equation, which in turn allowed the equation to be used to calculate all of the parameters associated with it. The parameters of the empirical equations (Equations (18) and (19)), which were determined for the Gumbel and LPT III distribution methods, respectively, are presented in Table 4.

$$
\begin{aligned}
& I=\frac{234.020 T^{0.200}}{t^{0.681}} \\
& I=\frac{212.790 T^{0.228}}{t^{0.667}}
\end{aligned}
$$

Furthermore, goodness-of-fit tests were applied to determine which statistical distribution was the best fit among the various techniques. Table 5 presents the results of the chi-square goodness-of-fit test performed on an annual series of rainfall data. Table 5 shows that there is no statistically significant difference between the rainfall intensity values for all return periods, based on the results of the chi-square test performed on the dataset. This finding validates the usefulness of local IDF formulas instead of one general equation for the whole country because, as mentioned previously, the rainfall is unpredictable and erratic in both time and space.

Table 5. The results of the chi-square goodness-of-fit test on the annual maximum rainfall.

\begin{tabular}{ccc}
\hline & Chi Square $\left(\chi^{2}\right)$ & \\
\hline Return Periods (Year) & Gumbel Method & LPT III Method \\
\hline 2 & 0.255 & 0.095 \\
5 & 0.023 & 0.092 \\
10 & 0.080 & 0.103 \\
25 & 0.037 & 0.049 \\
50 & 0.006 & 0.0002 \\
100 & 0.167 & 0.098 \\
\hline
\end{tabular}

\section{Conclusions}

In this study, IDF curves and IDF empirical formulas were derived for rainfall durations $(10,20,30,60,120,180,360,720$, and $1440 \mathrm{~min})$ for return periods $(2,5,10,25,50$, and 100 years) for Erbil city in the north of Iraq. The IDF curves were obtained using two different methods (Gumbel and LPT III). Although, the suitability of these distribution types has not been determined in this analysis, in order to maintain consistency with previous studies, we decided to use the same methodology as other researchers. The rainfall IDF curves developed in this study are immensely useful in the estimation of rainfall intensity for the design of flood control structures and water resources.

In this research, it was discovered that there is no significant difference between the results of the Gumbel and LPT III methods. Results in this study show that the IDF curves for Erbil city are fully fit to predict the values of rainfall intensities after subjecting the results to calibration and checking the empirical equation with the coefficient of determination $\left(R^{2}=1\right)$ and the accepted chi-square values. In addition, the derivation of IDF formulas is useful to make an approximate prediction more easily in comparison to IDF curves. The findings of the study are consistent with the findings of previous studies conducted in some parts of the study area. The findings confirmed that each province must have its own set of IDF curves because Iraqi cities differ in terms of topography and climate. However, despite the promising results, there are still some issues. The study's validity could not be checked because there were not any recorded data on shorter-duration rainfall events. Analysis only examines the statistical relationship between the variables and does not reveal their physical mechanism. 
The findings of this study can be used effectively as a guideline for urban water resource management, particularly in the design of storm water systems. As far as we are aware, no such analysis exists in the studied area. In fact, it would be beneficial to validate the results of this study using some new techniques, such as satellite-based precipitation, in order to confirm their accuracy. Additionally, the study's findings and developed IDF curves will be useful in the field of research on flash flood mitigation in the studied area, as well as in the preparation of different flood risk maps and scenarios.

Author Contributions: D.A.K., Conceptualization, methodology, writing-original draft preparation; A.R.M.A., conceptualization, methodology, formal analysis; A.M., data curation, investigation, writing-reviewing and editing; M.I.Y., supervision; M.S., writing—review and editing, validation, supervision. All authors have read and agreed to the published version of the manuscript.

Funding: This research received no external funding.

Institutional Review Board Statement: Not applicable.

Informed Consent Statement: Not applicable.

Data Availability Statement: Not applicable.

Conflicts of Interest: The authors declare no conflict of interest.

\section{References}

1. Al-Amri, N.S.; Subyani, A.M. Generation of rainfall intensity duration frequency (IDF) curves for ungauged sites in arid region. Earth Syst. Environ. 2017, 1, 8. [CrossRef]

2. Dehghani, M.; Salehi, S.; Mosavi, A.; Nabipour, N.; Shamshirband, S.; Ghamisi, P. Spatial analysis of seasonal precipitation over Iran: Co-variation with climate indices. ISPRS Int. J. Geo-Inf. 2020, 9, 73. [CrossRef]

3. Dupont, B.; Allen, D.L. Revision of the Rainfall-Intensity Duration Curves for the Commonwealth of Kentucky; University of Kentucky Transportation Center: Lexington, KY, USA, 1999.

4. Koutsoyiannis, D.; Kozonis, D.; Manetas, A. A mathematical framework for studying rainfall intensity-duration-frequency relationships. J. Hydrol. 1998, 206, 118-135. [CrossRef]

5. Bell, F.C. Generalized rainfall-duration-frequency relationships. J. Hydraul. Div. 1969, 95, 311-328. [CrossRef]

6. Chen, C.-L. Rainfall intensity-duration-frequency formulas. J. Hydraul. Eng. 1983, 109, 1603-1621. [CrossRef]

7. Hershfield, D.M. Estimating the probable maximum precipitation. J. Hydraul. Div. 1961, 87, 99-116. [CrossRef]

8. Miller, J.; Frederick, R.; Tracey, R. Precipitation frequency atlas of the conterminous western United States (by states). US Natl. Weather Serv. NOAA Atlas 1973, 2, 1-33.

9. Nhat, L.M.; Tachikawa, Y.; Takara, K. Establishment of intensity-duration-frequency curves for precipitation in the monsoon area of Vietnam. Annu. Disaster Prev. Res. Inst. 2006, 49b, 93-103.

10. Singh, V.P.; Zhang, L. IDF curves using the Frank Archimedean copula. J. Hydrol. Eng. 2007, 12, 651-662. [CrossRef]

11. Lima, C.H.R.; Kwon, H.-H.; Kim, Y.-T. A local-regional scaling-invariant Bayesian GEV model for estimating rainfall IDF curves in a future climate. J. Hydrol. 2018, 566, 73-88. [CrossRef]

12. Sun, Y.; Wendi, D.; Kim, D.E.; Liong, S.-Y. Deriving intensity-duration-frequency (IDF) curves using downscaled in situ rainfall assimilated with remote sensing data. Geosci. Lett. 2019, 6, 17. [CrossRef]

13. Kristvik, E.; Johannessen, B.G.; Muthanna, T.M. Temporal Downscaling of IDF Curves Applied to Future Performance of Local Stormwater Measures. Sustainability 2019, 11, 1231. [CrossRef]

14. Noor, M.; Ismail, T.; Shahid, S.; Asaduzzaman, M.; Dewan, A. Evaluating intensity-duration-frequency (IDF) curves of satellitebased precipitation datasets in Peninsular Malaysia. Atmos. Res. 2021, 248, 105203. [CrossRef]

15. Ombadi, M.; Nguyen, P.; Sorooshian, S.; Hsu, K.-L. Developing Intensity-Duration-Frequency (IDF) Curves From Satellite-Based Precipitation: Methodology and Evaluation. Water Resour. Res. 2018, 54, 7752-7766. [CrossRef]

16. Schardong, A.; Simonovic, S.P.; Gaur, A.; Sandink, D. Web-Based Tool for the Development of Intensity Duration Frequency Curves under Changing Climate at Gauged and Ungauged Locations. Water 2020, 12, 1243. [CrossRef]

17. Weinerowska-Bords, K. Development of local IDF-formula using controlled random search method for global optimization. Acta Geophys. 2015, 63, 232-274. [CrossRef]

18. Krvavica, N.; Rubinić, J. Evaluation of Design Storms and Critical Rainfall Durations for Flood Prediction in Partially Urbanized Catchments. Water 2020, 12, 2044. [CrossRef]

19. Al-Khalaf, H. Predicting Short-Duration, High-Intensity Rainfall in Saudi Arabia. Master's Thesis, King Fahd University of Petroleum and Minerals, Dhahran, Saudi Arabia, 1997.

20. Al-Shaikh, A. Rainfall Frequency Studies for Saudi Arabia. Master's Thesis, Civil Engineering Department King Saud University, Riyadh, Saudi Arabia, 1985. 
21. AlHassoun, S.A. Developing an empirical formulae to estimate rainfall intensity in Riyadh region. J. King Saud Univ. Eng. Sci. 2011, 23, 81-88. [CrossRef]

22. Elsebaie, I.H. Developing rainfall intensity-duration-frequency relationship for two regions in Saudi Arabia. J. King Saud Univ. Eng. Sci. 2012, 24, 131-140. [CrossRef]

23. Deger, I.; Yuce, M. Rainfall Intensity-Duration-Frequency Analysis for the City of Gaziantep. In Proceedings of the International Civil Engineering and Architecture Conference, Trabzon, Turkey, 17-20 April 2019; pp. 760-766.

24. Şen, Z. Annual daily maximum rainfall-based IDF curve derivation methodology. Earth Syst. Environ. 2019, 3, 463-469. [CrossRef]

25. Hadadin, N.A. Rainfall intensity-duration-frequency relationship in the Mujib Basin in Jordan. J. Appl. Sci. 2005, 5, 1777-1784. [CrossRef]

26. Hamaamin, Y.A. Developing of Rainfall Intensity-Duration-Frequency Model for Sulaimani City. J. Zankoy Sulaimani 2017, 19, p10634. [CrossRef]

27. Hasan, I.F.; Saeed, Y.N. Analysis of Rainfall Data for a Number of Stations in Northern Iraq. Al-Rafidain Eng. J. AREJ 2020, 25, 105-117. [CrossRef]

28. Mahdi, E.S.; Mohamedmeki, M.Z. Analysis of rainfall intensity-duration-frequency (IDF) curves of Baghdad city. In Proceedings of the IOP Conference Series: Materials Science and Engineering, Chennai, India, 16-17 September 2020; IOP Publishing: Bristol, UK, 2020; p. 012066.

29. Jalee, L.A.; Farawn, M.A. Developing rainfall intensity-duration-freqency relationship for Basrah City. Kufa J. Eng. 2013, 5, 105-112.

30. Majeed, A.R.; Nile, B.K.; Al-Baidhani, J.H. Selection of suitable PDF model and build of IDF curves for rainfall in Najaf city, Iraq Proc. J. Phys. Conf. Ser. 2021, 1973, 012184. [CrossRef]

31. Dakheel, A.A. Drawing curves of the rainfall intensity duration frequency (IDF) and assessment equation intensity rainfall for Nasiriyah city, Iraq. Univ. Thi-Qar J. 2017, 12, 63-82.

32. Nanekely, M.; Scholz, M.; Al-Faraj, F. Strategic framework for sustainable management of drainage systems in semi-arid cities: An Iraqi case study. Water 2016, 8, 406. [CrossRef]

33. Mustafa, A.M.; Muhammed, H.; Szydłowski, M. Extreme rainfalls as a cause of urban flash floods; a case study of the ErbilKurdistan region of Iraq. Acta Sci. Pol. Form. Circumiectus 2019, 18, 113-132. [CrossRef]

34. Mustafa, A.; Szydłowski, M. The impact of spatiotemporal changes in land development (1984-2019) on the increase in the runoff coefficient in Erbil, Kurdistan Region of Iraq. Remote Sens. 2020, 12, 1302. [CrossRef]

35. Mustafa Andam, S.M. The analysis of the influence of urbanisation on the runoff coefficient using remote sensing, GIS and hydrological modelling in Erbil-Kurdistan Region of Iraq. In Proceedings of the 6th IAHR Europe Congress, Warsaw, Poland, 15-18 February 2021; pp. 454-455.

36. Szydłowski, M.; Mikos-Studnicka, P.; Zima, P.; Weinerowska-Bords, K.; Hakiel, J.; Kalinowska, D. Stormwater and snowmelt runoff storage control and flash flood hazard forecasting in the urbanized coastal basin. In Proceedings of the 14th International Symposium Water Management and Hydraulic Engineering, Brno, Czech Republic, 8-10 September 2015; pp. 141-150.

37. Shareef, M.E.; Abdulrazzaq, D.G. River Flood Modelling For Flooding Risk Mitigation in Iraq. Civ. Eng. J. 2021, 7, 1702-1715 [CrossRef]

38. Kurdistan Region Statistics Office. Report of the Expectation of Kurdistan Region Population from 2009-2020; Kurdistan Region Statistics Office: Erbil-Kurdistan Region, Iraq, 2014.

39. Ramaseshan, S. Urban hydrology in different climatic conditions. In Lecture Notes of the International Course on Urban Drainage in Developing Countries; Regional Engineering College: Warangal, India, 1996.

40. Acar, R.; Senocak, S. Modelling of Short Duration Rainfall (SDR) Intensity Equations for Ankara, Turkey. In Proceedings of the BALWOIS 2008, Ohrid, Republic of Macedonia, 27-31 May 2008; pp. 1-9.

41. Oyebande, L. Deriving rainfall intensity-duration-frequency relationships and estimates for regions with inadequate data. Hydrol. Sci. J. 1982, 27, 353-367. [CrossRef]

42. Raiford, J.; Aziz, N.; Khan, A.; Powell, D. Rainfall depth-duration-frequency relationships for South Carolina, North Carolina, and Georgia. Am. J. Environ. Sci. 2007, 3, 78-84. [CrossRef]

43. Gumbel, E.J. Statistics of Extremes; Columbia University Press: New York, NY, USA, 1958.

44. Gumbel, E.J. The Return Period of Flood Flows. Ann. Math. Stat. 1941, 12, 163-190. [CrossRef]

45. Kotz, S.; Nadarajah, S.A. Extreme Value Distributions: Theory and applications; World Scientific: Singapore, 2000.

46. Nadarajah, S. The exponentiated Gumbel distribution with climate application. Environmetrics 2006, 17, 13-23. [CrossRef]

47. Sahoo, A.; Ghose, D.K. Flood Frequency Analysis for Menace Gauging Station of Mahanadi River, India. J. Inst. Eng. India Ser. A 2021, 102, 737-748. [CrossRef]

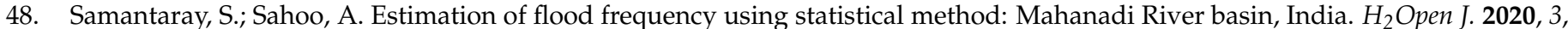
189-207. [CrossRef]

49. Yong, S.L.S.; Ng, J.L.; Huang, Y.F.; Ang, C.K. Assessment of the best probability distribution method in rainfall frequency analysis for a tropical region. Malays. J. Civ. Eng. 2021, 33. [CrossRef]

50. Chow, V.T.; Maidment, D.R.; Larry, W.; Mays. Applied Hydrology; Tata McGraw-Hill Education: New York, NY, USA, 1988.

51. Salman, S.A.; Shahid, S.; Ismail, T.; Rahman, N.B.A.; Wang, X.; Chung, E.-S. Unidirectional trends in daily rainfall extremes of Iraq. Theor. Appl. Climatol. 2018, 134, 1165-1177. [CrossRef] 
52. Al-Ansari, N. Management of water resources in Iraq: Perspectives and prognoses. Engineering 2013, 5, 667-684. [CrossRef] 53. Al-Ansari, N. Topography and climate of Iraq. J. Earth Sci. Geotech. Eng. 2021, 11, 1-13. [CrossRef] 